\title{
Enduring amnesia induced by ICV scopolamine is reversed by sesame oil in male rats $^{1}$
}

\author{
Shabnam-sadat Seyedi Tabari', Shirin BabriI ${ }^{I}$, Fariba Mirzaie ${ }^{\mathrm{III}}$, Fereshteh Farajdokht ${ }^{\mathrm{IV}}$, Gisou Mohaddes ${ }^{\mathrm{V}}$
}

DOI: http://dx.doi.org/10.1590/S0102-865020160080000004

IMSc, Neurosciences Research Center (NSRC), Tabriz University of Medical Sciences, Iran. Acquisition of data, technical procedures, manuscript preparation and writing.

IIFull Professor, NSRC, Tabriz University of Medical Sciences, Iran. Intellectual, scientific, conception and design of the study; critical revision.

IIIAssistant Professor, NSRC, Tabriz University of Medical Sciences, Iran. Acquisition of data, technical procedures.

${ }^{\mathrm{IV}} \mathrm{PhD}$, NSRC, Tabriz University of Medical Sciences, Iran. Acquisition of data, technical procedures.

vAssociate Professor, Drug Applied Research Center, Tabriz University of Medical Sciences, Iran. Intellectual, scientific, conception and design of the study; analysis and interpretation of data; manuscript preparation and writing; final approval.

\section{ABSTRACT}

PURPOSE: To evaluated the long-term effect of scopolamine and sesame oil on spatial memory.

METHODS: Memory impairment induced by Intracerebroventricular (ICV) injection of scopolamine hydrochloride (10 $\mu \mathrm{g} / \mathrm{rat}$ ). Animals were gavaged for 4 weeks with saline, sesame oil $(0.5,1$, or $2 \mathrm{~mL} / \mathrm{kg} / \mathrm{day})$, or 3 weeks with memantine (30 mg/kg/day) in advance to induction of amnesia. Morris water maze (MWM) test was conducted 6 days after microinjection of scopolamine. Then, blood and brain samples were collected and evaluated for the malondialdehyde (MDA) levels, superoxide dismutase (SOD) and glutathione peroxidase (GPX) activities, and total antioxidant status (TAS) and ferric reducing ability of plasma (FRAP).

RESULTS: Scopolamine significantly decreased traveled distance and time spent in target quadrant in probe test. Pretreatment of rats with sesame oil $(0.5 \mathrm{mg} / \mathrm{kg})$ mitigated scopolamine-induced behavioral alterations. Measurement of MDA, SOD, and GPX in brain tissue, and FRAP and TAS in blood showed little changes in animals which had received scopolamine or sesame oil.

CONCLUSIONS: Intracerebroventricular injection of scopolamine has a residual effect on memory after six days. Sesame oil has an improving effect on spatial memory; however this effect is possibly mediated by mechanisms other than antioxidant effect of sesame oil. Key words: Dementia. Scopolamine Hydrobromide. Sesame Oil. Spatial Memory. Oxidative Stress. Rats. 


\section{Introduction}

Alzheimer's disease (AD) is the most prevalent, severe, and disabling cause of dementia and an important cause of morbidity and mortality in the world ${ }^{1-3}$. Dementia of the Alzheimer type is a progressive, fatal neurodegenerative condition characterized by deterioration in cognition and memory, progressive impairment in the ability to carry out activities of daily living ${ }^{4}$. A number of neuropsychiatric symptoms are reported with $\mathrm{AD}$ such as problems with memory, thinking, and behavior ${ }^{5}$. Similarities in the memory deficits between Alzheimer patients and scopolamine treated animals have been reported ${ }^{6}$. Effects of cholinergic antagonists such as scopolamine are very like the destruction of cholinergic neurons in the hippocampus or performance associated with cognitive impairment caused by Alzheimer's disease ${ }^{7}$. Some studies have shown that oxidative stress plays an important role in the occurrence of neurodegeneration in Alzheimer's disease ${ }^{8}$. Oxidative stress is a critical detriment factor stimulating neuronal cell death ${ }^{9}$. Recently it is stated that scopolamine-induced disorders are associated with changes in the state of oxidative stress in the brains of rats ${ }^{10}$.

Sesame oil is a strong antioxidant dietary source for human ${ }^{11}$. Previous studies have shown that sesame oil has improving effects on memory and learning. Consumption of sesame oil during pregnancy and lactation increased passive avoidance learning of rats' offspring ${ }^{12}$. Also, sesame oil improved learning and memory in diabetic rats and in a streptozotocin induced Alzheimer's model in rats ${ }^{13,14}$. It is believed that neurophysiological effects of sesame oil on the learning process may be due to its antioxidant effects ${ }^{15}$.

Since, scopolamine-induced memory impairment is associated with brain oxidative stress and oxidative stress is one of the risk factors in Alzheimer's disease ${ }^{10}$, we aimed to investigate the effect of sesame oil on scopolamine model of dementia.

\section{Methods}

Animals used in this study were provided by the colony of Tabriz university of Medical Sciences. Adult male Wistar rats $(200-250 \mathrm{~g})$ were housed in standard cages in a temperature controlled room $\left(22-24^{\circ} \mathrm{C}\right)$, humidity $(40-60 \%)$, and light period (12h dark-12h light). Food and water were available ad libitum. All experiments were performed in agreement with guidelines of the Tabriz University of Medical Sciences for care and use of laboratory animals.
Sixty male Wistar rats were randomly divided into six $(n=10)$ experimental groups:

- Sham-operated controls

- Scopolamine group: these animals received ICV injection of scopolamine $(10 \mu \mathrm{g})$

- Scopolamine-sesame oil groups: these animals received sesame oil $(0.5,1$ or $2 \mathrm{ml} / \mathrm{kg})$ for 4 weeks before scopolamine injection

- $\quad$ Scopolamine - memantine group: these animals were treated with memantine $(20 \mathrm{mg} / \mathrm{kg} / \mathrm{day})$ for 3 weeks before injection of scopolamine

Dose and duration of treatment with memantine were chosen based on a previous study ${ }^{16}$.

\section{Induction of dementia}

Animals were anesthetized by intraperitoneal injection of ketamine hydrochloride $(60 \mathrm{mg} / \mathrm{kg})$ and xylazine $(6 \mathrm{mg} / \mathrm{kg})$. Then were placed in a stereotaxic apparatus (Stoelting, Wood Dale, IL, USA), and a single dose of scopolamine $(10 \mu \mathrm{g})$ was injected in their left ventricle $(\mathrm{AP}=-0.92 \mathrm{~mm} ; \mathrm{ML}=1.6 \mathrm{~mm} ; \mathrm{DV}=3.5 \mathrm{~mm})^{17}$.

\section{Morris Water Maze Test}

The water maze apparatus was a black circular pool with a diameter of $130 \mathrm{~cm}$ and a height of $80 \mathrm{~cm}$, filled with water 20 $1^{\circ} \mathrm{C}$ to a depth of $60 \mathrm{~cm}$. The maze was divided into four equal quadrants, and release points were designated at each quadrant as N, E, S, and W. A hidden circular plexiglas platform (10-cm diameter) was located in the center of the northeast quadrant, submerged $1.5 \mathrm{~cm}$ under the surface of the water. Fixed, extra maze visual cues were mounted at different locations around the maze. Performances were recorded with a video tracking system (HVS Image, Hampton, United Kingdom).

One week after induction of dementia, rats were trained and tested in the water maze according to our two days protocol. On the first day, the single training session consisted of eight trials within two consecutive blocks (four trials in each block and 5 min intervals between the blocks). A probe trial was performed on the second day, consisted of $60 \mathrm{~s}$ free swimming period without a platform. Time spent and traveled distance in the target quadrant was measured. In order to assess animal's sensory and motor coordination or the animal motivation the capability of rats to escape to a visible platform was tested 5 min after completion of probe tests $^{18}$ (Figure 1). 


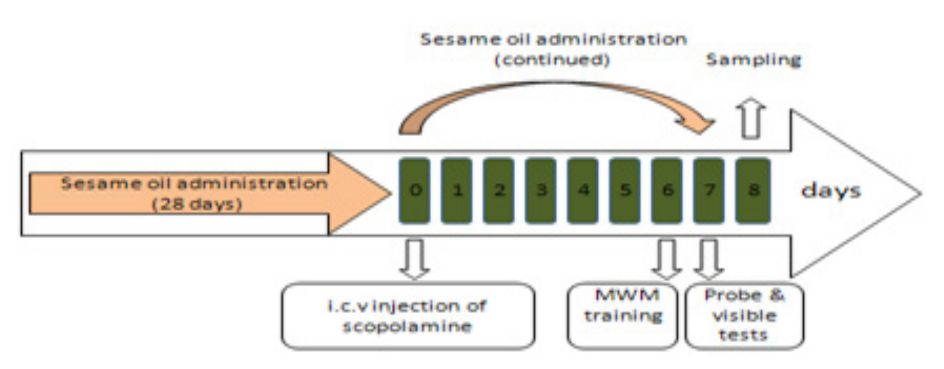

FIGURE 1 - Time line of sesame oil treatment, behavioral test, and samplings. MWM (Morris Water Maze)

\section{Tissue processing and homogenate preparation}

At the end of experiments, rats were deeply anesthetized with ketamin $(60 \mathrm{mg} / \mathrm{kg})$ and xylasin $(6 \mathrm{mg} / \mathrm{kg})$, blood samples were collected from heart and then animals were decapitated. Immediately, brains were excised, frozen in liquid nitrogen and stored at deep freeze $\left(-70^{\circ} \mathrm{C}\right)$ for later measurements. For antioxidant activities measurement, the brain samples were homogenized in $1.15 \% \mathrm{KCl}$ solution. The homogenates were centrifuged at 1000 rpm for $1 \mathrm{~min}$ at $4^{\circ 19}$. Then, brain tissue homogenate were used for determination of MDA levels, and activities of SOD and GPX. MDA, FRAP, and TAS of blood samples were also measured.

\section{Measurement of oxidative stress}

To determine the levels of lipid peroxidation, MDA as a marker of oxidative stress was used. MDA levels were measured using the thiobarbituric acid-reactive substances (TBARS) method $^{20}$. Glutathione peroxidase activity in brain tissue and blood was measured according to Paglia and Valentine using Randox (Randox, United Kingdom) ${ }^{21}$. Tissue superoxide dismutase was measured by a spectrophotometric method based on the inhibition of a superoxide-induced reduced nicotinamide adenine dinucleotide (NADH) oxidation according to Paoletti et al. ${ }^{22}$.

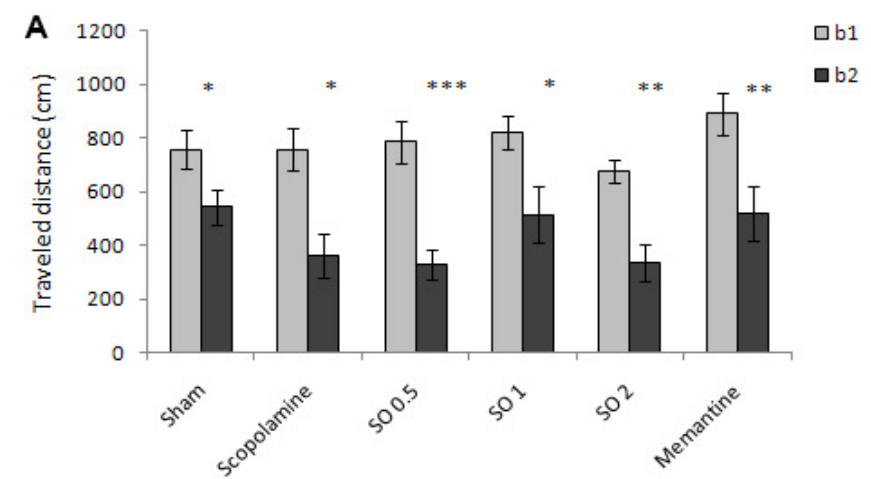

\section{Statistical analysis}

Results were analyzed using the SPSS version 16.0. Data for traveled distance and escape latency of block 1 and block 2 were compared by paired samples t-test. One-way analysis of variance (ANOVA) followed by the least significant difference (LSD) test was used to compare differences between means in more than two groups. Results are expressed as Means \pm SEM. The significant level was set at $\mathrm{p}<0.05$.

\section{Results}

\section{Effect of scopolamine and sesame oil on Morris Wa- ter Maze task}

During acquisition (first day of experiment including block 1 and block 2), escape latency and traveled distance indicated learning in locating the hidden platform, while more time spent and long distance traveled in the target quadrant in probe test (second day without platform) indicated better spatial memory.

Results of our study indicated that during acquisition, the performance of all groups improved with subsequent block of training. The Student $t$-test showed a significant difference in traveled distance and escape latency between the block 1 and 2 in all groups (Figure 2). The paired $t$-test for the traveled distance revealed a significant difference between two blocks in all groups; sham $(\mathrm{p}<0.05)$, scopolamine $(\mathrm{p}<0.05)$, sesame oil 0.5 $\mathrm{ml} / \mathrm{kg}(\mathrm{p}<0.001)$, sesame oil $1 \mathrm{ml} / \mathrm{kg}(\mathrm{p}<0.05)$, sesame oil $2 \mathrm{ml} / \mathrm{kg}$ $(\mathrm{p}<0.01)$, and memantine $(\mathrm{p}<0.01)$ groups. The paired $t$-test for the escape latency revealed a significant difference between two blocks in all groups, in sham $(\mathrm{p}<0.05)$, scopolamine $(\mathrm{p}<0.01)$, sesame oil $0.5 \mathrm{ml} / \mathrm{kg}(\mathrm{p}<0.001)$, sesame oil $1 \mathrm{ml} / \mathrm{kg}(\mathrm{p}<0.05)$, sesame oil $2 \mathrm{ml} / \mathrm{kg}(\mathrm{p}<0.01)$, and memantine $(\mathrm{p}<0.05)$ groups.

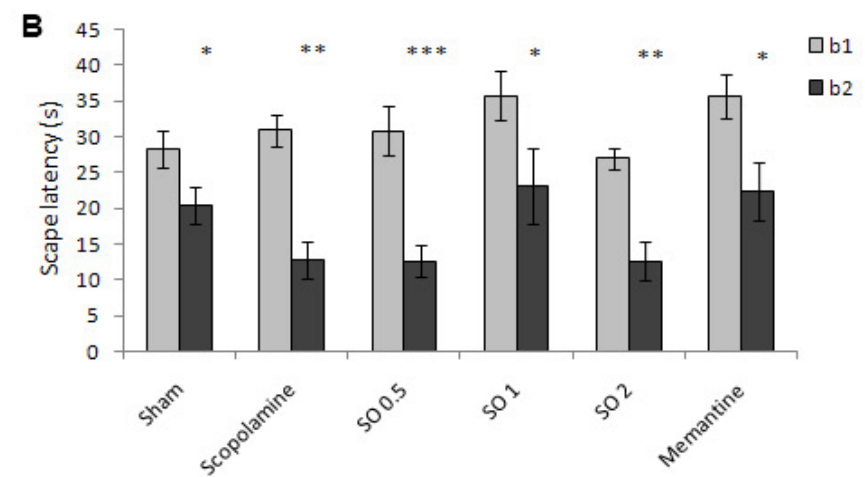

FIGURE 2 - Effects of scopolamine and different doses of sesame oil on traveled distance (A) and escape latency (B) to find the hidden platform. Each block represents the average of four consecutive trials. ${ }^{*} \mathrm{p}<0.05,{ }^{* *} \mathrm{p}<0.01$, and ${ }^{* * *} \mathrm{p}<0.001$ indicates the difference between Blocks 1 and 2 (b1 and b2) in each group. 
Values of the percent of traveled distance and time spent in target quadrant are shown in Figure 2A and B. Oneway ANOVA in probe test revealed significant differences in the percent of traveled distance and time spent in target quadrant among the groups.

The percentage of distance traveled $(\mathrm{p}<0.05)$ and the time spent $(\mathrm{p}<0.05)$ in the target quadrant for the scopolamine group was significantly less in comparison with sham group, indicating noticeable memory impairment in this group. Administration of sesame oil in dose of $0.5 \mathrm{ml} / \mathrm{kg}$ exert a significant $(\mathrm{p}<0.05)$ enhancing effect on these parameters. Whereas, animals receiving $1 \mathrm{ml} / \mathrm{kg}$ and $2 \mathrm{ml} / \mathrm{kg}$ doses of sesame oil and memantine did not show any significant differences with scopolamine group, indicating that memory has not improved in these group (Figure $3)$.

A

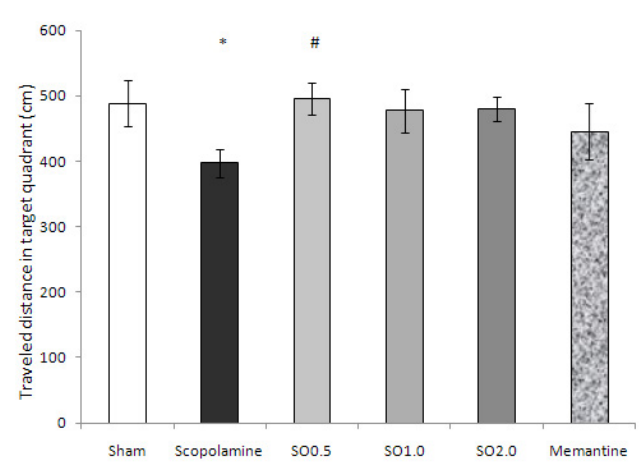

B

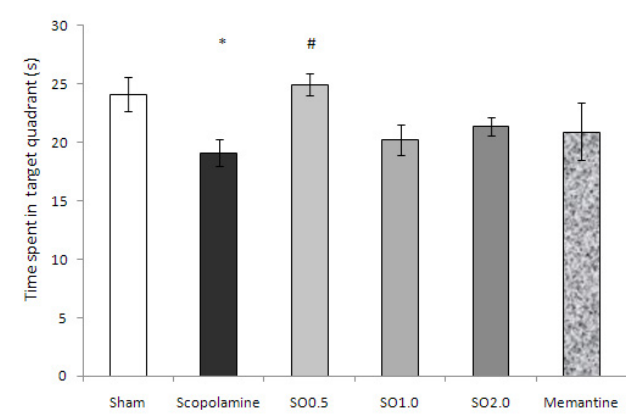

FIGURE 3 - Effects of scopolamine and different doses of sesame oil on the percentage of traveled distance (A) and time spent (B) in target quadrant. Values are the mean \pm SEM $(n=8-10) .{ }^{*} p<0.05$ and ${ }^{* *} \mathrm{p}<0.01$ indicates the difference relative to the control group and $\# \mathrm{p}<0.05$ indicates the difference relative to scopolamine group.

The effect of pre-training scopolamine or sesame oil on the escape latency and traveled distance in the visible platform test is depicted in Figure 4. There were no significant differences of performance among the groups on visible platform day for escape latency or for traveled distance, and speed of movement (not shown).

$\mathbf{A}$

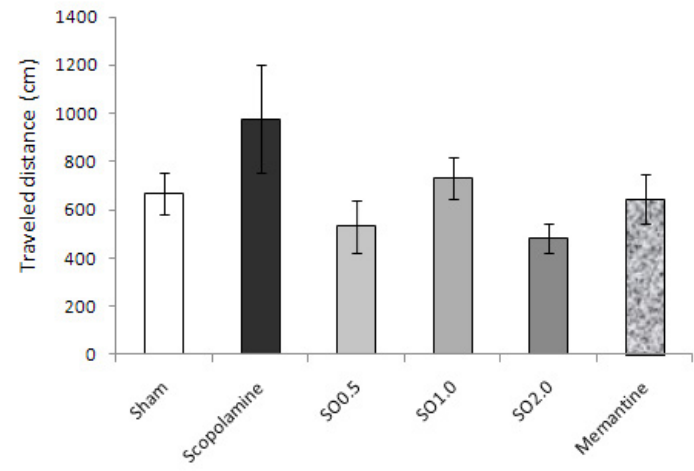

B

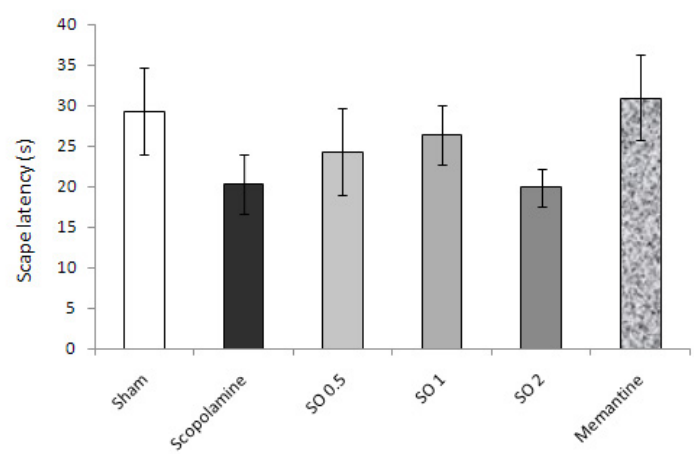

FIGURE 4 - Effects of scopolamine and different doses of sesame oil on traveled distances (A) and escape latency (B) in the visible platform test. There were no significant differences between the various groups.

\section{Effect of scopolamine and sesame oil on oxidative stress parameters}

Measurement of serum and brain MDA levels 6 days after injection of scopolamine did not show a significant change. The effect of sesame oil treatment on serum and brain MDA levels also was not significant (Table 1) except for the sesame oil with dose of $0.5 \mathrm{mg} / \mathrm{kg}$ that significantly $(\mathrm{p}<0.05)$ reduced brain SOD levels in comparison with sham and scopolamine groups and sesame oil with dose of $2 \mathrm{mg} / \mathrm{kg}$ that significantly reduced brain GPX activity in comparison with sham group. Three weeks of memantine pretreatment significantly $(\mathrm{p}<0.05)$ increased serum MDA levels in comparison to both sham and scopolamine groups. 
TABLE 1 - Effect of sesame oil on biochemical parameters of serum and brain tissue six days after ICV injection of scopolamine (One-way ANOVA analysis).

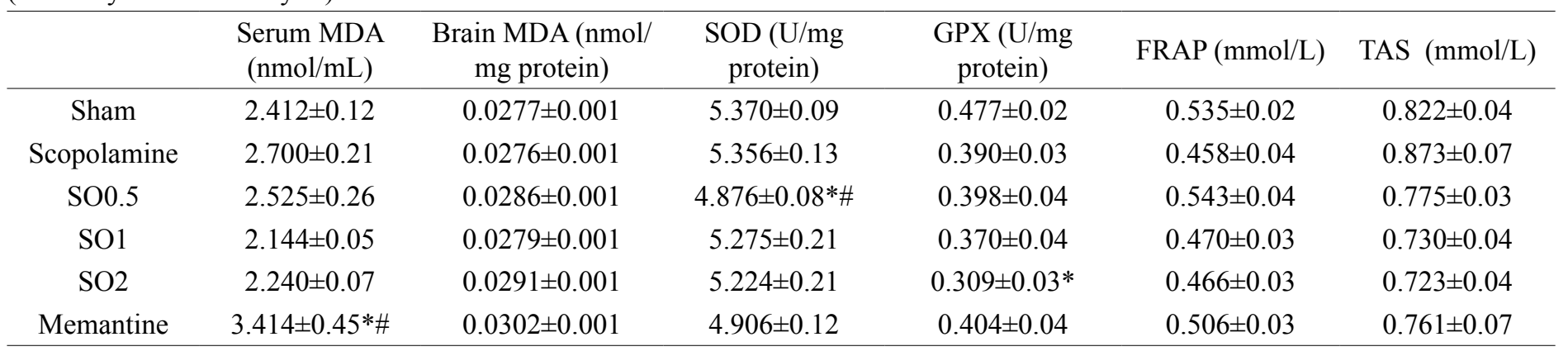

\section{Discussion}

The present study showed that ICV scopolamine microinjection has long-lasting effects on the rats' Morris Water Maze performance. Scopolamine did not significantly change acquisition phase of learning, however the retrieval phase was significantly impaired. Also, four weeks of pretreatment with dose of $0.5 \mathrm{ml} / \mathrm{kg}$ of sesame oil significantly reversed memory deficit induced by scopolamine and this indicates that sesame oil restored the spatial memory in demented rats.

Scopolamine-induced amnesia is a very well recognized animal model of memory dysfunction, widely used to test potential drugs of anti-Alzheimer's properties ${ }^{23}$. Enduring effect of scopolamine on memory impairment has been shown by Seifhosseini and colleague recently ${ }^{24}$. Scopolamine as a muscarinic cholinergic receptor antagonist impairs memory function ${ }^{6}$. It is well established that the cholinergic neurotransmission system in the basal forebrain plays an important role in learning and memory ${ }^{25}$. Also, destruction of cholinergic neurons or their function in the hippocampus is associated with cognitive impairment caused by Alzheimer's disease ${ }^{26}$. Moreover, scopolamine-induced amnesia is connected with increased oxidative stress in structures associated with learning and memory ${ }^{27}$. Oxidative stress, in turn, is a critical detriment factor leading to neuroinflammation and loss of cognitive function in Alzheimer's disease, Parkinson's disease, and multiple sclerosis $^{28}$. Therefore, utilization of antioxidants or substances that boost cholinergic neurotransmission can improve learning and memory and may be useful in prevention and treatment of Alzheimer's disease.

In support of our findings, memory improving effects of sesame oil have been shown in several studies. Six weeks of feeding with a diet containing sesaminol glucosides protected mice against beta-amyloid peptide-induced cognitive deficits ${ }^{29}$. Fathi and colleagues showed that 28-day pretreatment of rats with sesame oil prevented spatial memory deficit in streptoztocin- induced Alzheimer model in rats ${ }^{14}$. Asle Iranifam and colleagues also indicated that diet containing $10 \%$ sesame oil during pregnancy and lactation increased passive avoidance memory in rats' offspring ${ }^{12}$. Furthermore, findings of Hovayda's study showed that sesame oil increased learning in both castrated and intact animals ${ }^{30}$.

In the present study MDA levels (as a lipid peroxidation marker) of serum and brain tissue did not significantly change after six days in scopolamine treated animals. Also, GPX and SOD activities of the brain tissue were not significantly influenced by scopolamine. Three possibilities are likely in this regard. First, whole brain, nor cortex and hippocampus, was used for oxidative stress assays because their amount to measure various biochemical parameters was insufficient. Therefore, changes in the MDA and enzyme levels are not exclusive to learning and memory related structures. Second, non-enzymatic adaptive changes by the body; such as vitamin $\mathrm{E}$ mobilization ${ }^{31}$, may have counteracted the oxidative stress. Third, MDA and enzyme levels have returned to normal values by physiological body neutralizing scopolamineinduced oxidative stress after six days.

Sesame oil pretreatment in the present study did not significantly change MDA levels of serum and brain tissue. Also antioxidant assays on serum FRAP and TAS, and brain SOD and GPX did not show significant alterations except for sesame oil $0.5 \mathrm{mg} / \mathrm{kg}$ and $2 \mathrm{mg} / \mathrm{kg}$ that reduced SOD and GPX levels, respectively. Sesame oil is one of the best resources for polyunsaturated fatty acids (PUFA) ${ }^{32}$. Sesame oil protects against lipid peroxidation by increasing enzymatic and non-enzymatic antioxidant mechanisms ${ }^{13}$ although in our study enzymatic mechanisms were negligible. Therefore, vitamin E (tocopherol) in sesame oil may have provided a non-enzymatic defense against the free radicals damage ${ }^{33}$.

Furthermore, in this study it is possible that oral administration of sesame oil has directly corrected scopolamineinduced cholinergic dysfunction ${ }^{34}$. Alternatively, sesame oil as a 
neuroprotective agent which contains sesamin and sesamolin may have acted on the membrane fluidity of hippocampal neurons and number of dendrite branches, neural synapses, and synapse efficiency ${ }^{12,13,35}$. However, further investigation is required to clarify this issue.

\section{Conclusion}

Sesame oil protects against cognitive deficits induced by intracerebroventricular scopolamine in rats, and this effect may be mediated by mechanisms other than its antioxidant properties.

\section{References}

1. Wang X, Wang W, Li L, Perry G, Lee HG, Zhu X. Oxidative stress and mitochondrial dysfunction in Alzheimer's disease. Biochim Biophys Acta. 2014;1842(8):1240-7. PMID: 24189435.

2. Mohajeri MH, Troesch B, Weber P. Inadequate supply of vitamins and DHA in the elderly: Implications for brain aging and Alzheimertype dementia. Nutrition. 2014;31 (2):261-75. PMID: 25592004.

3. Small DH, Cappai R. Alois Alzheimer and Alzheimer's disease: a centennial perspective. J Neurochem. 2006;99(3):708-10. PMID: 17076655.

4. Jalbert JJ, Daiello LA, Lapane KL. Dementia of the Alzheimer Type. Epidemiol Rev. 2008;30 (1):15-34. PMID: 18635578.

5. Bales KR, Tzavara ET, Wu S, Wade MR, Bymaster FP, Paul SM, Nomikos GG. Cholinergic dysfunction in a mouse model of Alzheimer disease is reversed by an anti-A $\beta$ antibody. J Clin Invest. 2006;116(3):825-32. PMID: 16498501.

6. Jahanshahi M, Nikmahzar EG, Yadollahi N, Ramazani K. Protective effects of Ginkgo biloba extract (EGB761) on astrocytes of rat hippocampus after exposure with scopolamine. Anato Cell Biol. 2012;45(2):92-6. PMID: 22822463.

7. Azami NS, Piri M, Jahanshahi M, Oryan SH, Babapour V, Zarrindast MR. The role of CA1 $\alpha$ - adrenoceptor on scopolamine induced memory impairment in male rats. Physiol Pharmacol. 2010;14(1):66-77.

8. Ghasemi Z, Fakharzadeh S, Nazaran MH, Janahmadi M. Investigation of the effects of new synthetic iron nanchelator on neuronal excitability in the presence and absence of the oxidative stress. Physiol Pharmacol. 2012;16(2):95-106.

9. Pushpalatha B, Venumadhav N, Swathi M, Butchi raju A. Neuroprotective effect of resveratrol against scopolamine-induced cognitive impairment and oxidative stress in rats. Arch Biol Sci. 2013;65(4):1381-6.

10. Goverdhan P, Sravanthi A, Mamatha Th. Neuroprotective effects of meloxicam and selegiline in scopolamine-induced cognitive impairment and oxidative stress. Int J Alzheimer's Dis. 2012;2012:974013. PMID: 22536538.

11. Saleem MTS, Chetty MC, Kavimani S. Putative antioxidant property of sesame oil in an oxidative stress model of myocardial injury. J Cardiovasc Dis Res. 2013;4(3):177-81. PMID: 24396257.

12. Asle Iranifam N, Najafzadeh H, Papahn A, Moazedi A, Pourmehdi M. Effect of sesame oil consumption on the passive avoidance memory of rat offspring during pregnancy. Physiol Pharmacol. 2011;15 (2):268-76

13. Zare K, Fatemi Tabatabaei SR, Shahriari A, Jafari RA. Effect of butter and sesame oils on avoidance memory of diabetic rats. Iran J Diabetes Obesity. 2011;3(2):65-71.
14. Fathi F, Hatami H, Ali AR, Banan Khojasteh SM. Effects of sesame oil on improving spatial memory in Alzheimer's disease. J Babol Univ Med Sci. 2014;16(2):34-41.

15. Kesmati, M., Mard-Soltani, M., Khajehpour, L. Anxiogenic effects of acute injection of sesame oil may be mediated by $\beta-1$ adrenoceptors in the basolateral amygdala. Adv Pharm Bull. 2014;4(1):35-42. PMID: 24409407.

16. Al-Hazmi MA, Rawi SM, Arafa NM, Wagas A, Montasser AO. The potent effects of ginseng root extract and memantine on cognitive dysfunction in male albino rats. Toxicol Ind Health. 2015;31(6):494509. PMID: 23406953.

17. Abbasi E, Nassiri-Asl M, Sheikhi M, Shafiee M. Effects of vitexin on scopolamine-induced memory impairment in rats. Chin J Physiol. 2013;56 (3):184-9. PMID: 23656220.

18. Babri Sh, Amani M, Mohaddes G, Mirzaei F, Mahmoudi F. Effects of intrahippocampal injection of ghrelin on spatial memory in PTZinduced seizures in male rats. Neuropeptides. 2013;47(5):355-60. PMID: 23790400.

19. Omrani H, Alipour MR, Mohaddes G. Ghrelin improves antioxidant defense in blood and brain in normobaric hypoxia in adult male rats. Adv Pharm Bull. 2015;5(2):283-8. PMID: 26236669.

20. Kaya H, Sezik M, Ozkaya O, Dittrich R, Siebzehnrubl E, Wildt L. Lipid peroxidation at various estradiol concentrations in human circulation during ovarian stimulation with exogenous gonadotropins. Horm Metab Res. 2004;36(10):693-5. PMID: 15523594.

21. Paglia DE, Valentine WN. Studies on the quantitative and qualitative characterization of erythrocyte glutathione peroxidase. J Lab Clin Med. 1967;70(1):158-69. PMID: 6066618.

22. Paolleti F, Aldinucci D, Mocali A, Caparrini A. A sensitive spectrophotometric method for the determination of superoxide dismutase activity in tissue extracts. Anal Biochem. 1986;154(2):53641. PMID: 3089061

23. Kanwal A, Mehla J, Kuncha M, Naidu VGM, Gupta YK, Sistla R. Anti-amnesic activity of vitex negundo in scopolamine induced amnesia in rats. Pharmacol Pharm. 2010;1(1):1-8. doi: 10.4236/ pp.2010.11001.

24. Seifhosseini S, Jahanshahi M, Moghimi A, Aazami NS. The effect of scopolamine on avoidance memory and hippocampal neurons in male wistar rats. Bas Clin Neurosci. 2011;3(1):9-15.

25. Blake MG, Krawczyk MC, Baratti CM, Boccia M. Neuropharmacology of memory consolidation and reconsolidation: Insights on central cholinergic mechanisms. J Physiol Paris. 2014;108(4-6):286-91. PMID: 24819880.

26. Sirviö J. Strategies that support declining cholinergic neurotransmission in Alzheimer's disease patients. Gerontology. 1999;45 (1):3-14. PMID: 9876213.

27. Pachauri SD, Tota S, Khandelwal K, Verma PR, Nath C, Hanif K, Shukla R, Saxena JK, Dwivedi AK. Protective effect of fruits of Morinda citrifolia L. on scopolamine induced memory impairment in mice: a behavioral, biochemical and cerebral blood flow study. J Ethnopharmacol. 2012;139(1):34-41. PMID: 22107832.

28. Uttara B, Singh AV, Zamboni P, Mahajan RT. Oxidative stress and neurodegenerative diseases: a review of upstream and downstream antioxidant therapeutic options. Curr Neuropharmacol. 2009;7(1):65-74. PMID: 19721819.

29. Um MY, Ahn JY, Kim S, Kim MK, Ha TY. Sesaminol glucosides protect beta-amyloid peptide-induced cognitive deficits in mice. Biol Pharm Bull. 2009;32(9):1516-20. PMID: 19721225.

30. Hovayda R, Moazedi AA, Rasek A. The effect of sesame oil injection into CA1 area of hippocampus on spatial learning and memory, and its interaction with sexual steroids in adult male rats. J Rafsanjan Uni Med Sci. 2004;3(2):76-86. 
Tabari SS et al.

31. Elsayed NM. Antioxidant mobilization in response to oxidative stress: a dynamic environmental-nutritional interaction. Nutrition. 2001;17(10):828-34. PMID: 11684389.

32. Chen PR, Chien KL, Su TC, Chang CJ, Liu TL, Cheng H, Tsai C. Dietary sesame reduces serum cholesterol and enhances antioxidant capacity in hypercholesterolemia. Nutrition Res. 2005;25(6):559 67. doi: 10.1016/j.nutres.2005.05.007.

33. Moazedi AA, Moosavi M, Chinipardaz R. The effect of estrogen on passive avoidence memory in an experimental model of Alzheimer's disease in male rats. Physiol Pharmacol. 2011;14(4):416-25.

34. Mohamed MM, Mohamed EAK. Sesame oil modulates scopolamineinduced Alzheimer-like pathological dysfunction in rats. Int J Sci Res. 2016;5(1):70-4.

35. Cheng F, Jinn T, Hou RCW, Tzen JTC. Neuroprotective effects of sesamin and sesamolin on gerbil brain in cerebral ischemia. Intr $\mathrm{J}$ Biomedical Sci. 2006;2(3):284-8. PMID: 23674992.

\section{Acknowledgements}

To Dr Javad Mahmoudi and Dr Saeed Sadigh eteghad for their guide and technical assistance, Memantine was a kind gift from Sobhan Daru, Iran.

\section{Correspondence:}

Dr. Gisou Mohaddes

Drug Applied Research Center, Tabriz University of Medical Sciences

Phone/Fax: +98-41-33364664

mohaddesg@tbzmed.ac.ir

gmohades@yahoo.com

Received: Apr 11, 2016

Review: Jun 13, 2016

Accepted: July 12, 2016

Conflict of interest: none

Financial source: Neuroscience Research Centre, Tabriz University of Medical Sciences

${ }^{1}$ Research performed at Neurosciences Research Center (NSRC), Tabriz University of Medical Sciences, Iran. 